\title{
CONGENITAL HEART BLOCK
}

\author{
BY \\ R. W. SMITHELLS* and E. B. OUTON \\ From St. James' Hospital, Leeds
}

(RECEIVED FOR PUBLICATION NOVEMBER 28, 1958)

Congenital heart block is an uncommon condition. Before 1920 only seven acceptable cases had been recorded. With the widespread introduction of clinical electrocardiography further examples were reported from all parts of the world and when Yater, Lyon and McNabb (1933) reviewed the subject they were able to collect 44 cases which satisfied their diagnostic criteria.

Since then many more instances of congenital heart block have been recognized but, despite the increasing number of reports, few include anatomical and histological findings. In a recent survey of the subject Donoso, Braunwald, Jick and Grishman (1956) could find records of autopsies in only 17 instances, with adequate histological studies in seven.

These seven cases are summarized in the accompanying table together with an eighth case here reported. A further case (Wallgren and Winblad, 1937, Case 1) is also included although no E.C.G. is available and the criteria of Yater (1929) are therefore not fulfilled. However, there can be little doubt that the infant had congenital heart block (Table 1).

\section{Case Report}

Peter W. was born on May 8, 1957, weighing $6 \mathrm{lb} .1 \mathrm{oz}$. His mother had had one previous child and four miscarriages. She had rheumatic heart disease and a past history of pulmonary tuberculosis. She had been well throughout the pregnancy. One of her brothers had died at the age of 6 months with congenital heart disease.

The foetal heart rate was about 60 per minute before labour began. During labour the midwife recorded the same rate. The baby was born by breech delivery and showed blue asphyxia. He was given artificial respiration, oxygen and stimulants and recovered in about 20 minutes. Thereafter he became dyspnoeic and cyanosed during feeds. These symptoms became more marked and at the age of 2 days he was transferred to St. James' Hospital, Leeds, under the care of Dr. E. C. Allibone.

\footnotetext{
* Present address : Department of Child Health, Alder Hey Hospital, Liverpool 12.
}

On admission his temperature was $97^{\circ}$ F. $\left(36^{\circ} \mathrm{C}\right.$ ), pulse 48 per minute and respirations 60 per minute. When quiet he was a good colour but when crying or feeding he became cyanosed. The heart size could not be determined accurately. No thrill was felt. There was a loud, blowing systolic murmur audible over the entire praecordium. The femoral pulses were present. There was no oedema. The lungs were clear.

The clinical diagnosis was congenital heart disease with heart block. An E.C.G. showed complete atrioventricular dissociation with an atrial rate of 130 per minute and a ventricular rate of 47 per minute (Fig. 1).

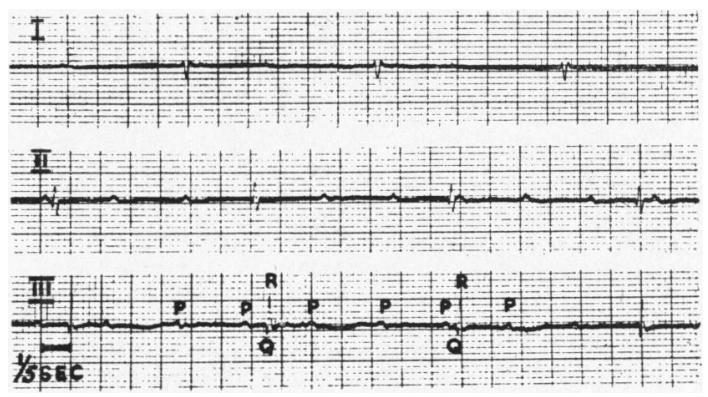

FIG. 1.-E.C.G. showing complete heart block.

He was nursed in oxygen and was taken out only for feeds which he took reasonably well from a bottle. Later his condition deteriorated and he was fed by oesophageal tube.

At the age of 4 days an apical diastolic murmur was clearly audible in addition to the systolic murmur. Two days later his temperature rose to $101^{\circ} \mathrm{F} .\left(38.4^{\circ} \mathrm{C}\right.$.) and he remained febrile until he died at the age of 9 days. No change in the pulse rate was noted when the temperature rose.

Pathology. At autopsy the brain showed widespread subarachnoid haemorrhage, which was considered to be anoxic in origin. Many areas of haemorrhage and collapse were seen in the lungs, especially in the lower lobes.

The heart weighed $38 \mathrm{~g}$. (after fixation in 10\% formalin). Apart from slight dilatation of both ven- 


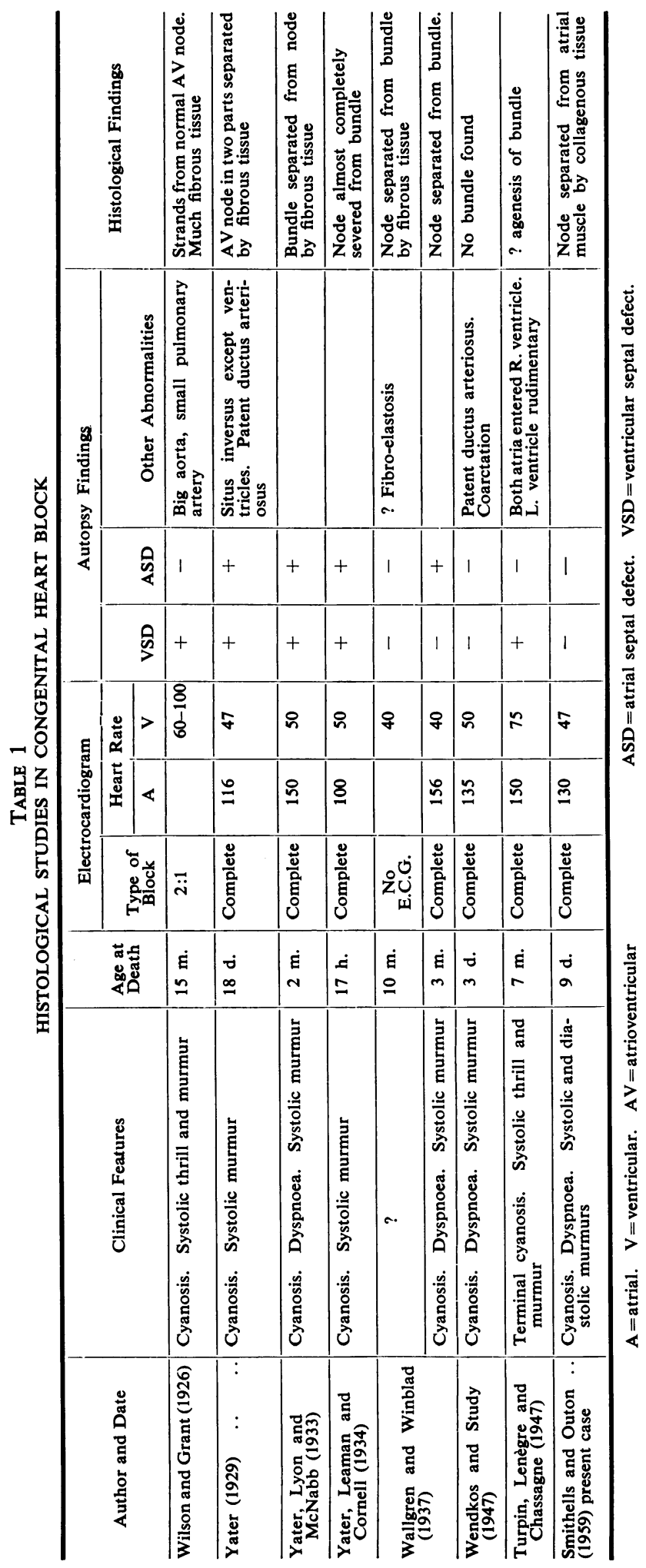


tricles it appeared normal with fully developed interatrial and interventricular septa. The foramen ovale and ductus arteriosus were probe patent. All other organs appeared normal.

Two blocks from the heart and two blocks from each lung were kept and embedded in paraffin for histological examination.

The first block from the heart was taken from the right atrium and included its junction with the superior vena cava and the upper half of the crista terminalis. It was sectioned transversely from above downwards. The second block included the lower two-thirds of the interatrial septum and the upper two-thirds of the interventricular septum. In it the septa were sectioned transversely, from behind downwards and forwards.

Each section was $10 \mu$ thick and every tenth section was mounted. Of these, the first and every succeeding tenth section were stained with haematoxylin and van Gieson. Section 54 of block 2 was later restained with phosphotungstic acid haematoxylin.

The lung blocks were cut transversely from the middle of each of the main lobes, sectioned at $6 \mu$ and stained with haematoxylin and eosin (Figs. 2, 3, 4).

Heart. In sections 3 to 48 of block 1 the sinoauricular node was seen as a wedge-shaped mass of interlacing muscle fibres and fine connective tissue surrounding the nodal artery and lying between the more clearly defined bundles of atrial muscle.

One hundred and thirty-eight sections from block 2 were examined in order to study the condition of the atrio-ventricular node and bundle. A small area of muscle appeared in the right side of the lower interatrial septum (section 52, Fig. 2). It was surrounded by collagenous connective tissue, continuous on the left with the aortic ring and above and anteriorly with the septum membranaceum. In section 54 the area had become a compact bundle of pale, striated muscle receiving a small artery (Figs. 3 and 4). This structure was regarded as the atrioventricular node. Its appear-

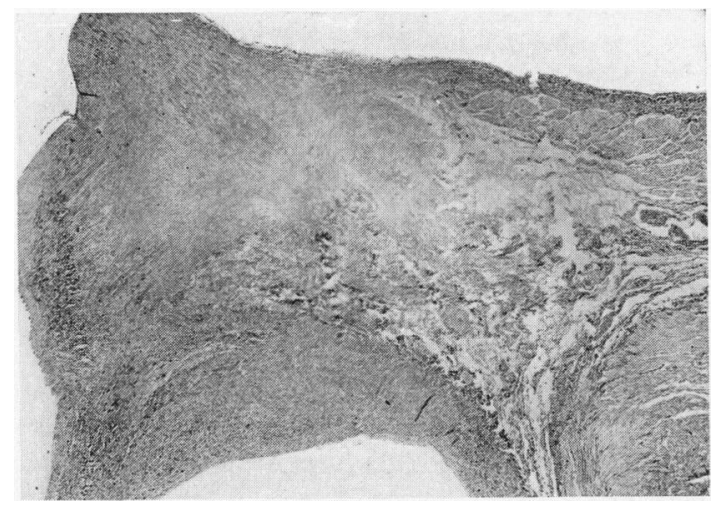

FIG. 2-Centre above, connective tissue enclosing small area of muscle. Right above, atrial muscle. Right below, ventricular muscle. Left below, aortic ring. Section 52. H. and van Gieson $\times 22$

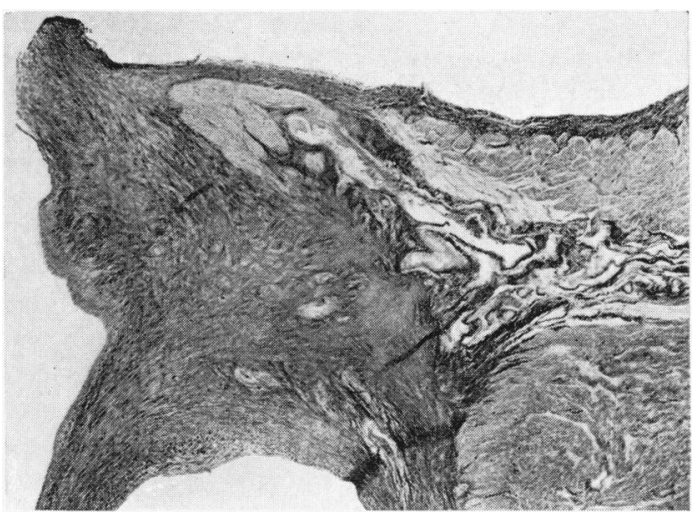

Fig. 3.-Atrioventricular node receiving small artery. Section 54. H. and van Gieson. $\times 16$.

ance agreed closely with the description of the full-term node given by Duckworth (1952). Its continuation as the bundle of His ran along the base of the septum membranaceum in succeeding sections. A branch passed down the left side of the interventricular septum, enclosed in a fine connective tissue sheath but the right branch was not clearly identified. No muscular connexion between the atrial myocardium and either the node or the ventricular myocardium was seen in the sections examined. No epithelial inclusions were seen in the septal tissues.

LUNGS. All sections showed patchy but widespread oedema and haemorrhage, usually associated with plugs of hyaline material in the alveolar ducts and terminal bronchioles.

The cause of the total heart block was considered to be a separation of the atrial myocardium from the atrioventricular node by collagenous connective tissue. The immediate cause of death was probably hyaline membrane disease. No infective cause of the pyrexia was found in the material examined.

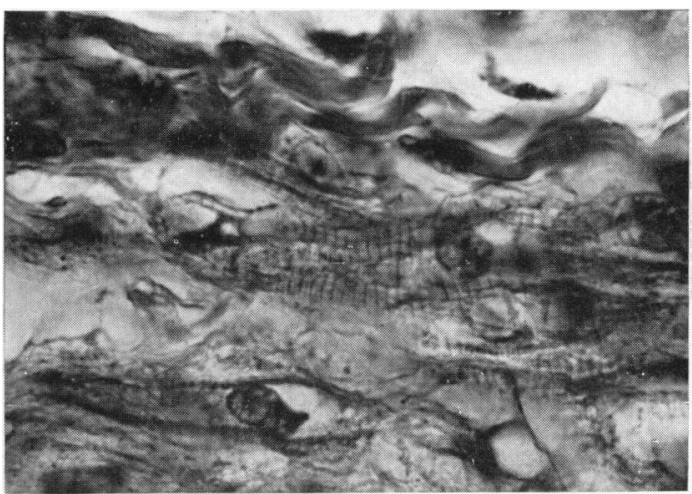

Fig. 4.-Part of atrioventricular node, showing striated muscle fibres Section 54. Phosphotungstic acid-haematoxylin. $\times 650$. 


\section{Discussion}

Patients dying with congenital heart block are frequently found to have ventricular septal defects at autopsy. This has given rise to some misunderstandings. First, ventricular septal defect has in the past been regarded as capable of causing heart block by anatomical interruption of the AV bundle. Second, it has been assumed that a patient with congenital heart block is likely to have a ventricular septal defect and such a lesion has often been diagnosed on the basis of a systolic murmur only. The presence of a diastolic murmur or cyanosis in some of these patients has been regarded as confirmatory evidence of an underlying malformation.

Development of the Conducting System. The development of the conducting system in the human heart is still a subject for debate but it has been established in the sheep (Field, 1951). First the atrioventricular bundle appears by differentiation in situ in the posterior and inferior walls of the common ventricle. The ventricular cavities are subsequently excavated on either side of the bundle so that it comes to lie in the free margin of the interventricular septum. Later the atrioventricular node arises by differentiation of tissue close to the central fibrous body. The bundle subsequently achieves anatomical and physiological continuity with the node. The sino-atrial node appears much later after the heart has started beating.

To result in complete atrioventricular dissociation the conducting system must be interrupted either at the AV node, or in the bundle above its bifurcation. This localization is confirmed by the normal QRS complexes usually seen on the E.C.G. The usual histological finding in congenital heart block is separation of the bundle from the node by fibrous tissue (see Table 1). In the case described above the node lacked continuity with the atrial muscle. In two reported cases (Wendkos and Study, 1947; Turpin, Lenègre and Chassagne, 1947) little or no conducting tissue has been identified. Rarely, heterotopic epithelial inclusions are found (Willis, 1958).

Even in the presence of gross malformations in the region of the AV node, continuity of the conducting tissues is usually achieved. In patients with large defects of the membranous interventricular septum, ostium primum defects and persistent A.V. canal, disturbances of conduction are only exceptionally found. The anatomy of the conducting system in these conditions has been demonstrated by Reemtsma and Copenhaver (1958).

Congenital Heart Block with Cardiac Malformations. In spite of earlier beliefs, there is no associa- tion between heart block and isolated ventricular septal defect. When these two disorders co-exist additional anomalies are almost invariably present. Of particular interest is the association of heart block, ventricular septal defect and corrected transposition of the great vessels. Walker, Cooley, McNamara and Moser (1958) operated on 69 children for closure of V.S.D. Three of them had associated corrected transposition and these all showed heart block.

\section{Congenital Heart Block without Malformations.} It is important to emphasize that congenital heart block may occur without any associated malformation. Indeed, this is probably the usual situation in patients surviving early childhood since uncomplicated congenital AV block is a relatively benign condition. Keith, Rowe and Vlad (1958) reported 23 cases of heart block in children of whom only six had associated anomalies. The almost invariable presence of heart malformations in children who die with heart block indicates that it is the malformations, not the dysrhythmia, which cause death.

Symptoms and Signs in Isolated Congenital Heart Block. Congenital heart block is usually symptomless although exertional dyspnoea is not uncommon in early life and Stokes-Adams attacks may occur. A systolic murmur is audible in about $90 \%$ of cases and mitral diastolic flow murmurs are not uncommon. Minor degrees of cardiac enlargement are usual.

Congenital heart block may be associated with intermittent or permanent cyanosis in early life which later disappears. White, Eustis and Kerr (1921) reported a mongol with congenital heart disease. At birth cyanosis was present and became more marked on crying. Five weeks later cyanosis was less marked and at the age of 11 weeks it had disappeared. Systolic and, later, diastolic murmurs were present and the clinical diagnosis was ventricular septal defect with patent ductus arteriosus.

Romberg and White (1924) describe an infant with heart block who was cyanosed at birth. At 9 months of age cyanosis was only seen when the child cried. At 10 months old, cyanosis was no longer seen. Systolic and diastolic murmurs were heard.

Aylward (1928) reported two siblings with congenital heart block. His clinical diagnosis was later given electrocardiographic support by Aitken (1932). The first child showed cyanosis and exertional dyspnoea when first seen but these had disappeared by the age of 6 years. There is no mention of a heart murmur. The second child was cyanosed only 
for the first 2 weeks of life and no murmur was heard.

Walker et al. (1958) report three children with heart block, V.S.D. and corrected transposition of the great vessels. One showed cyanosis up to the age of $\mathbf{8}$ years, after which it gradually disappeared.

An infant with complete heart block usually has a ventricular rate about one-third of normal. It seems improbable that this could be entirely compensated for by an increased stroke volume until the heart has had time to enlarge. Cardiac output will therefore be small and tissue oxygenation defective. On exertion oxygen demands increase, but no appreciable increase in heart rate is possible. Peripheral cyanosis is then likely to appear or become more marked. As the child grows the ventricular rate approximates more closely to the normal and the capacity of the ventricles increases. Exertional dyspnoea and cyanosis may then disappear.

\section{Summary}

The case is reported of an infant with congenital heart block who died at the age of 9 days. During life intermittent cyanosis with systolic and diastolic murmurs suggested a cardiac malformation but at autopsy the heart was macroscopically normal. Histological studies showed a normal atrioventri- cular node and bundle but the node was separated from atrial muscle by connective tissue.

We wish to thank Dr. E. C. Allibone for permission to publish this report; Dr. W. Goldie for the autopsy findings and the heart and lung specimens; and Professor R. A. Willis, Dr. G. M. Bonser and Dr. P. R. Evans for their helpful comments. We are indebted to Mr. G. Stansfield for cutting the sections and to Mr. J. Hainsworth for the microphotographs.

\section{REFERENCES}

Aitken, J. K. (1932). Lancet, 2, 1375.

Aylward, R. D. (1928). Brit. med. J., 1, 943.

Donoso, E., Braunwald, E., Jick, S. and Grishman, A. (1956). Amer. J. Med., 20, 869.

Duckworth, J. W. A. (1952). M.D. Thesis. Edinburgh.

Field, E. J. (1951). Brit. Heart J., 13, 129.

Keith, J. D., Rowe, R. D. and Vlad, P. (1958). Heart Disease in Infancy and Childhood, 1st ed. Macmillan, New York.

Reemtsma, K. and Copenhaver, W. M. (1958). Circulation, 17, 271

Romberg, E. C. and White, P. D. (1924). Boston med. surg. J., 190,

Turpin, R., Lenègre, J. and Chassagne, P. (1947). Arch. frans. Pédiat., 4, 617 .

Walker, W. J., Cooley, D. A., McNamara, D. G. and Moser, R. H. (1958). Circulation, 17, 249

Wallgren, A. and Winblad, S. (1937). Acta paediat. (Stockh.), 20, 175.

Wendkos, M. H. and Study, R. S. (1947). Amer. Heart J., 34, 138

White, P. D., Eustis, R. S. and Kerr, W. J. (1921). Amer. J. Dis. Child., 22, 299.

Willis, R. A.' (1958). The Borderland of Embryology and Pathology, 1st ed. Butterworth, London.

Wilson, J. G. and Grant, R. T. (1926). Heart, 12, 295

Yater, W. M. (1929). Amer. J. Dis. Child., 38, 112.

-, Leaman, W. G. and Cornell, V. H. (1934). J. Amer. med. Ass., $102,1660$.

-, Lyon, J. A. and McNabb, P. E. (1933). Ibid., 100, 1831. 